\title{
LOBBY EM AUDIÊNCIA PÚBLICA NO SUPREMO TRIBUNAL FEDERAL: INSTRUMENTOS DEMOCRÁTICOS PARA EFETIVAÇÁO DOS DIREITOS DA PERSONALIDADE FEMININA
}

\author{
LOBBY IN PUBLIC HEARING IN THE BRAZILIAN SUPREME COURT: \\ DEMOCRATIC INSTRUMENTS FOR THE REALIZATION OF THE \\ RIGHTS OF THE FEMALE PERSONALITY
}

\author{
Dirceu Pereira Siqueira ${ }^{\mathrm{I}}$ \\ Marcus Geandré Nakano Ramiro ${ }^{\text {II }}$ \\ Lorenna Roberta Barbosa Castro ${ }^{\mathrm{III}}$
}

\footnotetext{
I Universidade Cesumar, Maringá, PR, Brasil. Doutor em Direito

Constitucional.E-mail: dpsiqueira@uol. com.br
}

II Universidade Cesumar, Maringá, PR, Brasil. Doutor em Filosofia do Direito e do Estado. E-mail: marcus.ramiro@ unicesumar.edu.br

III Universidade Cesumar, Maringá, PR, Brasil. Mestranda em Ciências Jurídicas E-mail: lorennaroberta@hotmail.com
DOI: http://dx.doi.org/10.20912/rdc.v15i37.172

Recebido em: 10.08.2020

Aceito em: 05.092020
Resumo: $\mathrm{O}$ presente estudo objetiva identificar principais problemas das audiências públicas realizadas no Supremo Tribunal Federal, a fim de observar se grupos de interesses são mais eficaz que indivíduos que participam diretamente. Especificamente, busca analisar a necessidade dessa tutela aos direitos da personalidade feminina. A partir do cenário político brasileiro, a democracia e necessidade de uma cultura jurídica para conhecimento sobre direitos, garantias e formas de participaçáo, o que contribui para a justificativa do estudo, questiona-se em que medida o lobby, em audiência pública no STF, auxiliaria os direitos da personalidade feminina. O que se faz a partir do método dedutivo, com amparo na revisão bibliográfica, para levantamento dos principais estudos na área de direitos da personalidade, personalidade feminina, audiência pública no STF e lobby no judiciário. Os resultados mostram uma contribuição do lobby aos direitos das mulheres, que esbarram na dignidade humana, pois observou-se uma considerável influência na decisão final.

Palavras-chave: Audiência pública. Democracia. Direitos das mulheres. Direitos da personalidade. Lobby no judiciário.

Abstract: The present study aims to identify the main problems of public hearings held at the brazilian Supreme Court, in order to observe whether interest groups are more effective than individuals who participate directly. Specifically, it seeks to analyze the need for this protection of the rights of the female personality. From the Brazilian political scenario, democracy and the need for a legal culture for knowledge about rights, guarantees and forms of participation, which contributes to the justification of the study, it is questioned 
to what extent the lobby, in public hearing in the STF, would assist the rights of the woman personality. What is done from the deductive method, supported by the bibliographic review, to survey the main studies in the area of personality rights, female personality, public hearing in the STF and lobby in the judiciary. The results show a contribution by the lobby to women's rights, which run up against human dignity, as there was a considerable influence on the final decision.

Keywords: Public hearing. Democracy. Women's rights. Personality rights. Lobby in the judiciary.

\section{Introdução}

Audiências públicas, aqui objeto de estudo, é recorte artificial que se faz para análise, assim, não se busca esgotar a temática, pelo contrário, será reduzida ao âmbito da realização no Supremo Tribunal federal (STF) para possibilitar uma pesquisa adequada, em termos científicos. Referido Tribunal é responsável pelo controle concentrado de constitucionalidade e conforme as Leis no 9.868/99 e no 9.882/99, a primeira que regulamenta o processo e julgamento da Ação Direta de Inconstitucionalidade (ADI) e da Ação Declaratória de Constitucionalidade (ADC) e, a segunda sobre o processo e julgamento da Arguição de Descumprimento de Preceito Federal (ADPF), é possível que o relator da referida ação, ou o presidente do Tribunal, convoque a realização da audiência pública, regulamentada pelo Regimento Interno (STF).

Dentro desse universo amplo das audiências públicas, o estudo pretende investigar a participação popular naquele ato, realizado junto ao Supremo. A questão problema que o estudo buscará responder surge a partir de duas premissas, a primeira, maior, diz respeito à existência de um Estado democrático de direito, promulgado pela Constituição da República Federativa do Brasil de 1988, cujo poder emana de seus cidadãos, seja por eleição dos representantes, seja diretamente, para exercício desse poder, com legitimidade, então, de participação popular nas decisóes da Administração Pública (art. 1º, parágrafo único da Constituição). A segunda premissa em questão é que, esse mesmo Estado democrático de direito, se fundamenta na dignidade da pessoa humana (art. $1^{\circ}$, inciso III da Constituição), que além de diretriz ao ordenamento jurídico é fonte de direitos, como os direitos da personalidade. Nesse sentido, o estudo se aprofunda na seguinte problemática: em que medida a existência de lobby, em audiência pública no âmbito do STF, auxiliaria os direitos da personalidade feminina? E, levanta como entendimento preliminar que, tanto as audiências públicas, quanto a participação de grupos de interesse nessas são práticas de participação legítimas, sendo que a participação de interessados tem por finalidade a promoçáo e resguardo de interesses do grupo, aqui em estudo o grupo vulnerável em razão do gênero, por isso personalidade feminina, pois limitará ao 
interesse do direito (da personalidade) das mulheres. Aliás, o princípio e fundamento constitucional da dignidade da pessoa humana (art. $1^{\circ}$, inciso III da Constituição), que rege todo o ordenamento jurídico brasileiro deve atuar com a finalidade fundamental de tutelar, promover o bem dos indivíduos livre de qualquer discriminação em razão do sexo, conforme objetivo constitucional (art. $3^{\circ}$, inciso IV da Constituição). Dessa forma, a atuação em lobby nas audiências públicas junto ao Supremo em prol dos direitos das mulheres aparenta servir como instrumento de efetivação aos direitos da personalidade feminina.

Para desenvolvimento do estudo, como metodologia de abordagem foi utilizado o método dedutivo, a partir das duas premissas já delimitadas. Como metodologia de procedimento foi adotado o método de revisão bibliográfica para levantamento e análise dos principais trabalhos sobre: audiência pública no Supremo Tribunal Federal, lobby no judiciário, direitos da personalidade e direitos da personalidade feminina. Assim, feita consulta nas bases de dados selecionadas: Ebsco, SSRN, Biblioteca Digital UniCesumar e em revistas dos programas de pós-graduação com pesquisa relacionadas (Revista Jurídica Cesumar, Revista Enfoques, Revista Culturas Jurídicas, Revista Húmus, Revista juris poiesis e Revista brasileira de Estudos Constitucionais), além da biblioteca digital FGV, Scholar e biblioteca digital do Senado, pelos termos: "direitos da personalidade", "personalidade feminina", "participação feminina", "dignidade humana”, "audiência pública”, "audiência pública no judiciário”, "audiência pública no Supremo Tribunal Federal”, "participação democrática”, "mecanismo de participação constitucional", "grupos de interesse" "interesting groups", "lobby" e "lobbying”, sendo que. aos resultados, aplicou-se os filtros "relevância" e "última data de publicação". Assim, chegou-se ao número de 50 estudos selecionados para análise, dentre esses: dissertaçóes (4), tese de doutorado (1), publicações, artigos em revistas, periódicos e jornais científicos (25) e livros (20). Além, foram utilizados três diplomas jurídicos, consultados no site do Planalto, a saber: Constituição da República Federativa do Brasil de 1988, Lei no 9.868/99 e Lei no 9.882/99.

A partir dos trabalhos, náo se constatou o esgotamento da temática sobre audiências públicas no judiciário em prol dos direitos das mulheres e, especificamente em relação ao lobby no judiciário, há poucos estudos nacionais na área, embora mereça especial atenção acadêmica, na medida em que é meio lícito de participação e pressão de grupos aos direitos e interesses decisóes de cunho político, bem como o cenário político brasileiro atual necessita de atenção acerca da democracia e seus mecanismos de atuação, defesa democrática e participação popular.

A temática se mostra relevante, ainda, pela e pertinência com os interesses das ciências sociais, que se dedica a estudar as relaçóes sociedades, em especial àquelas que necessitam de especial atenção, como é o caso da temática feminina que, junto aos 
movimentos sociais femininos, tem se dedicado ao estudo da autonomia da mulher, da violência de gênero, da ausência de representatividade, da busca pela desconstrução de padrôes patriarcais ainda existentes.

Nesse sentido, o presente estudo tem como objetivo apresentar um panorama geral sobre as audiências públicas no Brasil, identificar as principais problemáticas desse instrumento democrático; observar a influência de grupos de interesse nas audiências públicas junto ao Supremo Tribunal Federal, assim como analisar a necessidade de proteção aos direitos da personalidade feminina.

Por fim, espera contribuir com os resultados da presente pesquisa às discussões acadêmicas acerca da participação popular nas decisões da Administração Pública, que contribui ao fomento dos estudos da democracia brasileira, assim como à cultura de informação jurídica que se faz necessária para propagas informaçóes acerca das possibilidades de participação, garantias e direitos dos cidadãos brasileiros.

\section{As Audiências Públicas no Brasil}

O presente capítulo busca investigar o instrumento democrático da audiência pública no âmbito nacional. Para tanto, se preocupará em apresentar sua origem, função e princípios básicos ao instituto para, em seguida, apreciar referido instrumento no âmbito do Supremo Tribunal Federal (STF). A apreciação que se fará, junto ao STF, se relaciona com a utilização e críticas existentes na literatura especializada. Dessa forma, esta seção se subdividirá em duas partes para o adequado desenvolvimento.

\subsection{Noçôes fundamentais e principiológicas sobre audiência pública}

A audiência pública é valioso instrumento democrático, na medida em que possibilita a participaçáo dos cidadáos direta e indiretamente - neste, quando os particulares são representados por associaçóes civis, organizaçóes etc. - nas decisóes da Administração Pública. Nesse sentido, Thiago Luis Sombra afirma que, "among instruments that seek to increase popular participation, public hearings are particularly notable in that they enable people to experience and provide authority on any given subject" (em traduçáo livre, "entre os instrumentos que buscam aumentar a participação popular, as audiências públicas são particularmente notáveis, pois permitem que as pessoas experimentem e forneçam suas experiências e proporcione autoridade sobre qualquer assunto") (SOMBRA, 2016, p. 668).

Originou-se na extensão do princípio da audiência individual ao princípio da audiência pública do direito anglo-saxão e se universalizou, no direito inglês é baseado no princípio da justiça natural e informa a garantia de defesa, no direito norte-americano é a garantia do devido processo legal (GORDILLO, 2014, p. XI-2), o princípio due process of 
law (DAL BOSCO, 2002, p. 148), no mesmo sentido (CASAGRANDE, 2018, p. 76). Em síntese, "public hearings are one of the most prominent tools of judicial review in Latin America" (em uma tradução livre, "as audiências públicas são uma das ferramentas mais importantes de revisão judicial na América Latina") (SOMBRA, 2016, p. 658).

No Brasil, particularmente, o instrumento se popularizou a partir da década de 90 e se consolidou como símbolo da democratizaçáo processual, tanto judicial quando administrativo (LIMA, 2015, p. 518), o que é validado pela constatação da promulgaçáo da Constituição da República Federativa do Brasil (CF), no ano de 1988, em superação ao regime ditatorial que era vigente, e instituiu o Estado democrático de direito (art. $1^{\circ}$, caput da CF). Neste Estado democrático de direito o poder passa a emanar, direta ou indiretamente, do povo (art. $1^{\circ}$, parágrafo único da $\mathrm{CF}$ ), em exercício da democracia. A democracia, aliás, não é um tudo ou nada, é questão de grau de comprometimento com a prática democrática e a sociedade pode muito com essas práticas, como organizar suas instituiçôes que, por sua vez, irá variar a profundidade da sua prática democrática (YOUNG, 2002, p. 05), isto é, da participação social.

Nesse comprometimento com a prática democrática das instituiçôes, como o Estado que assim se institui, passa a existir mecanismos de participação que incluem em seus procedimentos espaços e canais para a deliberação entre cidadáos e/ou seus governantes, como a audiência pública, nos termos de Maria Eberhardt, que, em suas palavras, destaca ainda o despertar para a visão de que a democracia por apenas seu mecanismo eleitoral não é suficiente para uma democracia real:

La audiencia pública, el plan estratégico, el presupuesto participativo, son algunos ejemplos. Esta opción dejaba entrever que la democracia electoral pura no alcanzaba por sí sola para una buena administración de los asuntos compartidos, sino que era posible, a la vez que recomendable, abrir nuevos canales a la participación popular, no sólo para la elección de los representantes, sino también, para la opinión y el debate de las cuestiones públicas quelos afectasen como ciudadanos, a fin de arribar a políticas más inclusivas y legítimas frente a la desconfianza generada por el accionar corporativo de los partidos y sus políticos. (EBERHARDT, 2015, p. 204)

Dessa forma, uma das possibilidades da participação democrática direta dos cidadãos é pelas audiências públicas. E se se pensar em uma base principiológica constitucional às audiências públicas, nível Brasil, envolverá, fundamentalmente, o princípio democrático (art. $1^{\circ}$, caput da $\mathrm{CF}$ ), da participação política (art. $1^{\circ}$, parágrafo único da CF) e o princípio da cidadania (art. $1^{\circ}$, inciso II da CF). Corrobora com essa premissa o entendimento de Diogo Moreira Neto que, em uma explicitação aos princípios em destaque, sublinha que o princípio democrático se manifesta como princípio da legitimidade a conformar o agir do Estado com a vontade popular e, necessariamente, está atrelado ao princípio da legalidade, para reger a conformidade do agir estatal; ainda, para o referido autor, o princípio democrático se desdobra no princípio da cidadania, que reconhece no povo o poder político de decisão sobre a coisa pública, e no princípio 
da participação política, que instrumenta esse poder de decisão, seja para escolha dos legisladores e governantes, seja para escolha do conteúdo político ou administrativo das decisóes públicas, consensualmente deliberadas, sendo que este último sentido se caracteriza como informativo da audiência pública (MOREIRA NETO, 1997, p. 1516).

A cidadania, especificamente, não se limita às liberdades negativas que os cidadãos podem reivindicar, isso porque, os direitos políticos envolvem, sobretudo, liberdades positivas, a possibilidade de participação comum, os sujeitos são coassociados livres e iguais (OLIVEIRA, 2007, p. 33). De outro lado, como destaca David Rúbio (2017, p. 57), se os membros da sociedade não possuem percepçáo sociocultural e popular ou desconhecem seus direitos, dificilmente participarão de um exercício de defesa desses direitos, o que ocorre com a cultura jurídica, que deve ser formada desde os direitos humanos para ensino, promoção conscientização e formaçáo, ainda para o autor, não se trata de educar os cidadáos para memorização dos artigos constitucionais, mas sim “enseñar a partir de una praxis acompañada por teorías, que nos conviertan en personas más activas y efectivas a nivel multi-escalar y desde una cultura de derechos humanos a tiempo completo y en todo lugar" (RUBIO, 2017, p. 57).

A conglomeração dos princípios constitucionais da cidadania, democracia e participação política destacados, também póe em pauta o que Stephan Kirst denominou de direito democrático de participação, isto é, no status ativo de colaboração do indivíduo, em que, ao decidir sobre seus direitos pode ser tratado como sujeito com capacidade de ação, esse status ativo de colaboração "seria então o fundamento tanto de um direito democrático de participação como também de um direito de ser ouvido nos processos administrativos e judiciais" (KIRST, 2016, p. 12).

Aliás, os cidadãos "are in effect the owners of the community, entitled and expected to shape and choose alternatives for the good of the community, not merely maximize their narrow self-interests" (em tradução livre, "os cidadãos são, de fato, os proprietários da comunidade, com o direito e a expectativa de moldar e escolher alternativas para o bem da comunidade, não apenas maximizar seus próprios interesses estreitos") (COCHRAN III, 2017, p. 23). Assim, os cidadãos devem realmente participar das decisões da Administração Pública, pois "uma Constituição vale mais pelo que significa em termos práticos, no plano vivo das instituições e das políticas públicas concretas, do que no discurso abstrato, e frequentemente vazio, de muitos juristas" (CASTRO, 2014, p. 731).

Para Diogo de Figueiredo Moreira Neto (1997, p. 14), audiência pública trata de processo administrativo aberto a grupos sociais determinados e indivíduos para aperfeiçoamento das decisões da Administração, "criado por lei, que lhe preceitua a forma e a eficácia vinculatória, pela qual os administrados exercem o direito de expor tendências, preferências e opçóes que possam conduzir o Poder Público a decisões de 
maior aceitação". Gustavo Oliveira (1997, p. 276) destaca que, mediante a realização da audiência pública, garante-se o direito de o cidadáo poder opinar, ser ouvido, no que diz respeito aos assuntos de interesse da coletividade.

O instrumento democrático da audiência pública, que possibilita a participação direta e indireta dos cidadãos a participarem das decisões da Administração Pública, tem por pressuposto, para sua realizaçáo, a existência de interesse coletivo e difuso, em termos gerais, indica que a decisão atingirá uma coletividade, isto é, transcende um direito individual, além da necessidade de previsão normativa para possibilitar a convocação da audiência pública que é marcada pela oralidade aos debates.

\subsection{Audiências Públicas no Supremo Tribunal Federal (STF)}

A presente parte do trabalho dedica-se à reuniáo dos principais estudos sobre a realização das audiências públicas no âmbito do Supremo Tribunal Federal (STF), com filtro ao papel esperado com a realização e a função prática revelada com o ato, para identificar as principais queixas, as principais problemáticas que o instrumento democrático tem revelado.

As audiências públicas envolvem necessariamente um interesse coletivo e difuso, assim como necessitam da previsão legal para sua convocação. Como sua base principiológica é constitucional, há previsóes tanto constitucionais, quanto infraconstitucionais. $\mathrm{Na}$ Constituição, a maioria das previsóes são genéricas (art. 29, inciso XII; art. 194, parágrafo único, inciso VII; art. 198, inciso III; art. 204, inciso II; art. 225, caput, todos da Constituição Federal), isto é, não foi expressamente previsto na redação constitucional da maioria das previsóes, mas os termos como cooperação, participação e, implicitamente, o dever da comunidade indicam a existência de previsão constitucional para a realização da audiência pública, o que não se observou ser problema, ou empecilho, nos estudos na área.

Nesse sentido, é de grande relevância as audiências públicas no Poder Judiciário, isso porque, além do trato de questóes complexas, intensas controversas, que envolvem a coletividade, requer um nível técnico de conhecimento por afetar valores socioculturais que estruturam a sociedade, parcela dessa ou segmentos sociais (VASCONCELOS; SOARES; 2015, p. 38).

No âmbito do Supremo Tribunal Federal (STF), que interessa ao presente estudo, há previsão da possibilidade de convocação pela lei de processo e julgamento de Ação direta de inconstitucionalidade (ADI) e ação declaratória de constitucionalidade (ADC), no art. 90, $\$ 1^{\circ}$ da Lei 9.868/99, assim como na lei de arguição de descumprimento de preceito fundamental (ADPF), em seu art. $6^{\circ}, \$ 1^{\circ}$ da Lei $n^{\circ} 9.882 / 99$, assim como a regulamentação está no Regimento Interno do Tribunal. Em todos os casos (ADI, ADC e ADPF), atribuiu-se competência ao Presidente ou ao Relator para convocar audiência 
sempre que entender por necessário o esclarecimento de questóes ou circunstâncias fáticas com repercussão geral e de interesse público relevante e caberá ao Ministro que presidir a audiência selecionar quem serão os participantes, determinar a ordem dos trabalhos e fixar o tempo de manifestação de cada um.

Mark Tushnet (2015, p. 17), ao buscar identificar algumas características das audiências públicas realizadas no Supremo Tribunal Federal (STF), destaca que se trata de mecanismos formais em que os pontos de vista da sociedade civil contemporânea são levadas ao Tribunal para deliberações, pois, em comparação, a Constituição brasileira se mostra razoavelmente aberta e participativa.

De outro lado, Lívia Gil Guimarães, em recente estudo empírico acerca das audiências públicas no Supremo Tribunal Federal, constatou parcial dissonância entre o discurso do Tribunal e a prática, na medida em que, nos discursos dos ministros, a finalidade da audiência pública serviria para instruir o Tribunal, democratizá-lo, no sentido de democracia participativa, legitimar as decisóes e criar um espaço de diálogo social (GUIMARÁES2020, p. 253), entretanto:

[...] ao se analisar conjuntamente todos os seus elementos constitutivos em exercício na prática, vê-se que esse mecanismo de participaçáo parece estar apto a atender apenas ao seu papel instrutório, deixando deficitárias as demais funçóes anunciadas nos discursos. Isso porque a ferramenta apresenta problemas i) de estrutura e organização; (ii) na seleção de participantes e (iii) na admissibilidade e na acessibilidade. Esses problemas levam a um questionamento sobre as outras funcionalidades elencadas na lista dos ministros do STF. (GUIMARÁES, 2020, p. 255).

A crítica da autora não é isolada nos estudos da área, Edilson Vitoreli Diniz Lima (2015, p. 523-524) destacou o papel limitado das audiências públicas, decorrente de problemas relativos tanto à sua forma, quanto à condução dos trabalhos, assim, notou a impossibilidade de colher opinióes do maior número de pessoas e produzir discussão qualificada, além da falta de participação social, que é reforçada pelos defeitos da própria organização, em que as autoridades encarregadas da convocação quase não se fazem presente. Em outro estudo, os resultados revelaram que as audiências públicas tiveram uma finalidade meramente retórica na deliberação judicial (SOMBRA, 2016, p. 689), também frisou a baixa participação dos juízes, bem como o fator discricionário para convocação:

On average, apart from the Rapporteur and the justice convening the hearing, less than two additional justices attend sessions. This variable explains the absence of information available from justices not presiding as the Rapporteur in these hearings. To a large extent, this variable directly relates to the fact that holding the hearings is the Justice Rapporteur's discretionary act and not subject to full bench deliberation at a plenary session. (Traduçáo livre: Em média, além do relator e da justiça que convocam a audiência, menos de dois juízes adicionais participam de sessóes. Essa variável explica a ausência de informaçóes disponível por juízes que não presidem o relator nessas audiências. Em grande medida, essa variável está diretamente relacionada ao fato de que 
realizar as audiências é o relator da justiça ato discricionário e não sujeito a deliberaçáo completa da bancada em sessão plenária) (SOMBRA, 2016, p. 661).

Em outro estudo restou constatado que a participação pela audiência pública indica "alguma efetividade como fonte de pressão e influência nessa arena. $\mathrm{O}$ motivo dessa aparente efetividade é o de que esse instrumento de litígio fornece informaçóes precisas e adicionais de cunho científico tanto à parte litigante, quanto à própria Corte" (GUIMARÁES, 2018, p. 23). E, nesse ponto, questiona-se o acesso efetivo à justiça, e esse acesso é ponto central do da moderna processualística, embora o conceito de efetividade, por si só seja algo vago, que poderia ser entendido como igualdade de armas, entretanto, efetividade perfeita, a igualdade total, é utópica, as diferenças entre as partes, os obstáculos ao acesso efetivo à justiça podem e devem ser atacados (CAPPELLETTI, 1998, p. 13-14).

Assim, embora as audiências públicas sejam um instrumento democrático para participação dos cidadáos, quando observado de forma mais próxima, o que aqui foi utilizado os estudos especificamente sobre as audiências públicas realizadas pelo Supremo Tribunal Federal, a prática das audiências tem revelado falhas ao instituto, em sua forma e condução. Dentre as principais queixas, identifica-se a baixa participação da sociedade, seja por desinformação, desconhecem as razóes, direitos em discussão e a possibilidade de participação, além da baixa participação dos próprios julgadores, a discricionariedade para convocação do ato, que depende do relator da ação ou do presidente do Tribunal. Além, ainda, da condução que obsta o diálogo pretendido, tanto em razão do tempo distribuído, quanto pela ordem de fala e disposição da própria mesa de trabalhos, com a presença de autoridades, que têm inibido a participação popular. Logo, se faz necessário o estudo de outro instrumento na tentativa de auxiliar a busca pela efetivaçáo dos direitos: o lobby.

\section{Lobby como atividade aliada às audiências públicas no STF}

Outro instrumento democrático de participação é o lobby, mas pouco estudado, talvez por ainda pairar certo estigma ${ }^{1}$. Ao presente estudo, lobby corresponde a "atividade de defesa de interesses afetados por decisóes políticas" (GOZETTO; MANCUSO, 2012, p. 03). O lobby tem por fundamento constitucional a livre manifestação de pensamento (art. 5º, inciso IV); a liberdade de "expressão da atividade intelectual, artística, científica e de comunicação" (art. 50, inciso IX); a liberdade de reunião em locais abertos (art. 50, inciso XVI); liberdade de associação (art. 5º, inciso XVII); direito de receber informação

1 A estigmatização do lobby se dá pela prática ilícita desse formato de pressão, em que se influencia em proveito de interesses egoísticos, como denunciado em escândalos de mensalão na política brasileira. No entanto, o termo lobby é neutro, comum e licitamente utilizado para defesa de grupos de interesse em assuntos políticos. Sobre o assunto, ver: (GOZETTO; MANCUZO, 2012). 
dos órgãos públicos, que trata do art. $5^{\circ}$, inciso XXXIII; e direito de petição aos poderes públicos (art. 5, inciso XXXIV, alínea “a”), que Andréa Gozetto e Wagner Mancuso (2012, p. 05) corroboram com essa fundamentação constitucional à atividade lícita de lobby.

Grupos de interesses buscam atingir seus objetivos de influenciar pelo lobby, que envolve três etapas, conforme o estudo de Clive Thomas, a saber, obter acesso aos atores políticos (policy makers), criar uma atitude de conduzir ao objetivo do grupo e, por último, tentar influenciar os formuladores de políticas:

Interest groups work to achieve their goal of influencing public policy through the activity of lobbying. The processo $f$ lobbying envolve three stages that may overlap in practice: first, gaining access to policy makers; second, creating an atitude among policy makers conducive to the group's goals; and third, influencing policy makers in the group's favor. Not all lobbying activity is directed to influence inmediate policy decisions. Some is intended to gain access or create na atmosphere - involving trust, credibility, and maybe even dependence of public officials on a group - that will be conducive to the group in shaping future government policy. (THOMAS, 2004, p. 06, grifos no original)

Lívia Guimarães (2020, p. 248) destaca que, dentre as principais formas de lobby no Poder Judiciário, especialmente no Supremo Tribunal Federal (STF), estão (i) o patrocínio de casos testes, a partir dos legitimados no art. 103 da Constituição; (ii) apresentação de amicus curiae, fundamentada nas Leis n. 9.868/99 e n. 9.882/99 e Regimento Interno do STF); (iii) a exposição em audiências públicas, também fundamentada pelas Leis n. 9.868/99, n. 9.882/99 e Regimento Interno do STF; (iv) reunião agendada com os ministros em seus gabinetes, legitimado pelo procedimento interno ao Tribunal) e; (v) apresentação de memoriais e notas técnicas (procedimento interno ao Tribunal).

"Lobbying in judicial affairs refers to the organization and management of influence by persons and groups who are not necessarily the principals in a litigation" ("o lobby em assuntos judiciais refere-se à organização e gerenciamento de influência por pessoas e grupos que não são necessariamente os principais em um litígio”, em tradução livre) (HAKMAN, 1966, p. 18). Dessa forma, há um certo engajamento pela causa que certamente influenciará, além da decisão, políticas futuras. Conforme o estudo de Andréa Gozetto e Wagner Mancuso, o lobby lícito ocasiona contribuiçóes positivas para os tomadores da decisão, para a opinião pública, aos interesses dos representados e ao sistema político como um todo (GOZETTO; MANCUSO, 2012, p. 05):

Os lobbies colaboram com a difícil tarefa dos tomadores de decisão ao proporcionarlhes informaçôes sobre os itens que figuram na agenda. Em um contexto em que são espeitados os direitos políticos mencionados anteriormente, os diferentes lados de uma mesma questão podem ter lobistas ativos, operando em controle mútuo. $\mathrm{O}$ confronto entre lobistas de interesses opostos pode ajudar o tomador de decisão a ter uma visão mais completa da questão em jogo, bem como a evitar decisóes apressadas e imperfeitas. Em outras palavras, os lobbies podem colaborar para o aprimoramento das decisóes 
tomadas, ajudando os tomadores de decisão a forjar soluçóes satisfatórias para as diversas partes legítimas envolvidas. (GOZETTO; MANCUSO, 2012, p. 05-06)

Pelos estudos já realizados, constata-se que o lobby exercido no Poder Judiciário se difere dos exercidos nos poderes Executivo e Legislativo, na primeira constataçáo seria "porque o tipo de contato permitido entre os lobistas e os tomadores de decisão é muito restrito. Grupos de interesse podem abordar juízes apenas através de funçôes estabelecidas em litígios" (OLSON, 2004, p. 179, tradução livre). Denise Albano destaca, por sua vez, um certo deslocamento dos grupos de pressáo dos poderes Executivos e Legislativos para atuarem junto ao Judiciário pela efetivaçáo dos direitos sociais (ALBANO, 2015, p.183). Em recente estudo, justificou-se na medida em que se dá de uma forma mais contida no Judiciário, em razão das regras e interações mais formais do Judiciário (GUIMARÃES, 2020, p. 248):

Por óbvio que realizar "lobby" no judiciário, ou ainda exercer influência nesse ramo do poder, como já dito anteriormente, é diferente de realizá-lo no Legislativo e no Executivo. No Judiciário, a atuação dos grupos é mais minimalista, na medida em que a participação nesse fórum é limitada por normas internas e regramentos específicos que restringem a abordagem, a aproximação dos atores envolvidos e a permeabilidade dialógica entre eles. Ademais, o termo "influência", aqui, deve ser interpretado de forma bastante restritiva, na medida em que em nada se relaciona com a noção de tráfico de influência, este último condenado pelas legislações. (GUIMARÁES, 2018, p. 06, grifos no original).

Em outro estudo, sobre litígio estratégico de grupos de interesse, Lívia Guimarães destacou que a influência dos grupos de interesse no Judiciário, quando comparada ao formato de lobby nos demais Poderes é um tanto quanto limitada e tem origem na forma da participação, que estáo fora da relaçáo jurídica ou dependem da autorização da Corte (amicus curiae) ou pela convocaçáo da audiência pública para que possam apresentar seu ponto de vista (GUIMARÁES, 2018, p. 23).

O lobby na audiência pública, que propicia a participação pluralista nesse formato, não se mostra ruim, entretanto deve ficar claro para os participantes e sociedade em geral, além do controle de acesso e admissáo, ademais, trará benefícios que ultrapassam os grupos individuais, poderá facilitar a decisão dos julgadores, incrementar os debates e até educar a sociedade (GUIMARÁES, 2020, p. 264), o que o presente artigo também defende.

Ponto de destaque se faz a tomada de decisão, em se tratando de estudo voltado ao STF. Niklas Luhmann ressalta em sua obra, que a "complexidade própria dum sistema de procedimento depende, essencialmente, da complexidade da tarefa de decisão. Esta, por sua vez, depende da medida em que as premissas de decisão devam ser pressupostas ou procurada" (LUHMANN, 1980, p. 46). Alerta Newton Albuquerque que, embora o judiciário tenha crescido em protagonismo, seus integrantes têm o dever de autocontenção e submissão institucional (ALBUQUERQUE, 2020, p.102). Em outra análise sobre a 
tomada de decisóes judiciais e políticas de grupos de interesse, Paul Collins Jr. constatou evidências de que os tomadores de decisão da Suprema Corte podem ser influenciados pela argumentação persuasiva apresentada, em resumos de amicus curiae, por interesses organizados (COLLINS JR, 2007, p. 65).

Como já foi salientado no tópico anterior, há uma certa dissonância constatada entre o discurso dos ministros do Supremo e a realidade da prática das audiências públicas, entretanto, a autora destaca que a arena das audiências públicas se mostra propícia ao comportamento estratégico de atores e atrizes que buscam realizar lobby frente aos tomadores de decisão, enquanto que os ministros e ministras estão a mapear os grupos de interesse que querem ouvir e, consequentemente, fortalecer sua autoridade na tomada de decisão (GUIMARÁES, 2020, p. 263). "Esta é, provavelmente, a teoria secreta do processo jurídico: que, através do envolvimento no desempenho dum papel, se pode captar a personalidade, reestruturá-la e motivá-la para a tomada de decisóes" (LUHMANN, 1980, p. 75).

Em um estudo sobre a ADPF no 54, acerca da interrupção da gestação de feto anencéfalo, Lívia Guimarães analisou o litígio estratégico praticado por um grupo de defensoras dos direitos das mulheres, na referida ADPF, que formou um grupo de interesse determinado a pressionar, debater e desmistificar as dúvidas em torno dos direitos associados à interrupçáo da gravidez dos fetos anencéfalos, o que possibilitou a atuaçáo do grupo de interesse no STF com objetivo de obter direitos e garantias associados ao gênero mulher (GUIMARÃES, 2018, p. 04-05):

No caso específico da ADPF 54, as entidades apresentaram amici curiae, no entanto, o entáo ministro relator do caso, Marco Aurélio Mello, optou por indeferir os pedidos de amici curiae, sob a justificativa de se tentar evitar tumulto processual. O ministro optou, então, por convocar audiências públicas. Logo, no que diz respeito à análise dos instrumentos de participaçáo na Corte, bem como sua possível influência, a avaliação da incorporação ou não dos argumentos das atrizes sociais que participaram processualmente do litígio estratégico praticado na ADPF 54, só foi possível por meio da análise de suas colaboraçôes em audiência pública convocada pelo ministro relator e realizada nos dias 26.08.2008, 28.08.2008, 04.09.2008 e 16.09.2008. (GUIMARÁES, 2018, p. 11-12, grifos no original).

Sobre a mesma ADPF, outro estudo destacou que o julgamento e a questão jurídica enfrentada foi considerada como o mais importante dos julgados do STF dos últimos anos, uma vez que com a chegada à Corte de casos e demandas sociais, desafiam a renovação do olhar do direito e da justiça à superar um discurso vazio dos juristas (DIANA, 2015 , p. 89). Ademais, ao analisar os 33 argumentos apresentados pelas atrizes sociais nas audiências públicas da ADPF no 54 e a incorporação, seja positiva ou negativa, desses argumentos nos votos, Lívia Guimaráes destacou que, além de influenciar a decisão final do Supremo, as “incorporaçóes dos argumentos geraram não só uma influência direta na decisão de cada ministro, como também foram capazes de gerar ônus argumentativo para 
aqueles que não seguiram a mesma linha de razoamento proposta pelas atrizes sociais" (GUIMARÁES, 2018, p. 23).

Assim, constata-se que os grupos de pressão, ou lobbies, no Poder Judiciário, mostra-se como forte aliados democráticos nas audiências públicas, na medida em que a participação no formato de lobby pode influenciar positivamente na decisão final ao alcance dos direitos de um grupo de interesse mais do que a participaçáo individual, isolada do cidadão, como se constatou a partir dos estudos da área, especificamente, acerca da ADPF no 54, que proporcionou uma visáo abrangente aos direitos das mulheres, para além da decisão da interrupçáo da gravidez de fetos anencéfalos, deu espaço para questionamento à autonomia e direitos do gênero mulher.

\section{Tutela dos Direitos da personalidade feminina por audiências públicas}

A presente seção cuida, por sua vez, de adentrar à indispensabilidade de proteção jurídica aos atributos e caracteres intrínsecos ao indivíduo, os direitos da personalidade, mas especificamente às mulheres, o que denomina de direitos da personalidade feminina. Para tanto, subdividirá em dois tópicos, primeiro, para uma breve introdução aos direitos da personalidade e, em seguida, aos direitos da personalidade feminina.

\subsection{Por uma compreensão dos direitos da personalidade}

Os direitos da personalidade encontram-se em constante expansão, tanto como disciplina de estudo, quanto os direitos em si, uma vez que correspondem à parcela da dignidade humana, o essencial individual que náo se resume a um rol de direitos. Ao Estado democrático de direito, instituído pela Constituição da República Federativa do Brasil de 1988, a dignidade humana é fundamento constitucional (art. $1^{\circ}$, inciso III), logo, é vetor desse Estado, suas normas, objetivo aos seus cidadãos e limite.

O princípio da dignidade humana, além de ser diretriz hermenêutica de todo o ordenamento jurídico brasileiro, vincula o Estado e os particulares, envolve prestaçóes positivas e negativas, é critério de identificação dos direitos fundamentais e fonte de direitos não enunciados na própria Constituição (SARMENTO, 2016, p. 98-99).

O termo personalidade advém do latim personalitas, de pessoa (persona) e quer significar o conjunto de elementos inerentes ou próprios da pessoa, que formam ou constituem um indivíduo que, em tudo, se diferencia de qualquer outro indivíduo (SILVA, 2003, p. 1.035). Nesse sentido, "a personalidade se resume no conjunto de caracteres do próprio indivíduo, que consiste na parte intrínseca da pessoa humana. Trata-se de um bem, no sentido jurídico, sendo o primeiro bem pertencente à pessoa, sua primeira utilidade" (SZANIAWSKI, 1993, p. 35), assim, cada indivíduo possui atributos, 
caracteres, essenciais que o diferencia dos demais e são essenciais ao seu desenvolvimento digno, ao respeito à sua pessoa.

Direito da personalidade é uma construção teórica, cujas raízes provêm das doutrinas germânicas e francesas da segunda metade do séc. XIX, e é relativo à tutela da pessoa humana, os direitos essenciais ante à necessidade de proteçáo à dignidade humana e sua integridade psicofísica (CANTALI, 2009, p. 28). Os direitos da personalidade buscam atender às emanaçóes da personalidade humana (ASCENSÃO, 2000, p. 75) e, como Cleide Fermentão (2006, p. 255) explicita, os direitos da personalidade são essenciais, necessários e vitais para o desenvolvimento da pessoa humana.

Os principais estudos da área há muito já se preocuparam em desfazer a confusão doutrinária entre direitos da personalidade e direitos fundamentais, sedimentando que não se confundem (SZANIAWSKI, 1993; CANOTILHO, 1999; ZANINI, 2011). Essa confusão, entretanto, certamente se deu na medida em a temática de direitos humanos e fundamentais se desenvolveu na modernidade, momento em que se passa a valorizar a pessoa humana e sua dignidade, são direitos históricos e universais que surgiram gradualmente e projetaram novas formas de direitos, os denominados novos direitos, elaborados pela necessidade permanente de proteção das necessidades humanas específicas, são relativos à personalidade humana, decorrente da dignidade e do respeito à pessoa (SILVEIRA; CARVALHO, 2019, p. 203-204).

José Joaquim Gomes Canotilho anotou que muitos direitos fundamentais são direitos da personalidade e cada vez mais aqueles tendem a ser direitos da personalidade, como o inverso também, devido à interdependência entre o estatuto positivo e negativo do cidadão e um direito geral da personalidade (CANOTILHO, 1999, p. 372), e, esse direito geral, ou cláusula geral do direito da personalidade é justamente a dignidade da pessoa humana que busca a promoção, desenvolvimento e proteção do ser humano.

Leonardo Zanini (2011, p. 60), por sua vez, também destaca que na Constituição brasileira há os direitos que, ao mesmo tempo, são direitos fundamentais e da personalidade, assim como, há os que sejam apenas fundamentais, que não se enquadram naquela outra categoria, assim como o inverso ocorre, no Código Civil há previsão de direitos que são especificamente da personalidade, mas não são direitos fundamentais. Miguel Reale sinaliza que os direitos da personalidade são aqueles inerentes ao indivíduo como um atributo à sua formação:

Poderíamos dizer, em suma, que são direitos da personalidade os a ela inerentes, como um atributo essencial à sua constituição, como, por exemplo, o direito de ser livre, de ter livre iniciativa, na forma da lei, isto é, de conformidade com o estabelecido para todos os indivíduos que compóem a comunidade. Como já disse, cada direito da personalidade se vincula a um valor fundamental que se revela através do processo histórico, o qual não se desenvolve de maneira linear, mas de modo diversificado e plural, compondo as várias civilizaçôes, nas quais há valores fundantes e valores acessórios, constituindo aqueles as que denomino invariantes axiológicas. Estas parecem inatas, mas assinalam os 
momentos temporais de maior duraçâo, cujo conjunto compóe o horizonte de cada ciclo essencial da vida humana. (REALE, online, grifos no original).

Nicola Frascati Jr. (2017, p. 44) ressalta que os direitos da personalidade realizam a proteção tanto à integridade física, psíquica quanto moral do homem, além de resguardar certos bens, assim considerados juridicamente, da personalidade, e exemplifica, como a vida, intimidade, honra, liberdades, segredos, sossego etc., sem que exista um rol taxativo a esse. Cumpre transcrever, por fim, a conclusão de Leonardo Zanini, em relação à caracterizaçâo dos direitos da personalidade, que resume o intento dessa parte do trabalho, que busca traçar noções básicas para compreensão do instituto:

Por conseguinte, podemos concluir que: a) os atributos da personalidade incluem-se no grupo dos bens jurídicos tutelados pelo ordenamento jurídico e são objeto de direito; b) a personalidade náo é o objeto dos direitos da personalidade, mas sim seus atributos, já que o "modo de ser da pessoa" não é a mesma coisa que "pessoa"; c) os atributos da personalidade são bens essenciais e preciosos para o ser humano; d) a sua qualificação como bens decorre do fato de que satisfazem necessidades humanas; e) esses bens não precisam ser configurados como realidade exterior ao sujeito; f) admite-se a existência de direitos sobre a pessoa de outrem, o que normalmente ocorre nas relaçóes de direito de família e não nos direitos da personalidade. (ZANINI, 2011, p. 103).

Para uma compreensão básica dos direitos da personalidade, portanto, verifica-se que esses direitos decorrem da dignidade da pessoa humana, princípio fundamental ao Estado democrático de direito brasileiro, conforme enunciado constitucionalmente (art. $1^{\circ}$, inciso III da Constituiçáo), e busca proteger os atributos e caracteres essenciais do indivíduo, que possibilita seu desenvolvimento como ser humano, por isso esbarra na parcela da dignidade humana.

\subsection{Tutela da personalidade feminina}

Reconhecida a existência dos direitos da personalidade e a necessidade de proteção aos caracteres e atributos individuais e essenciais do ser humano, tais como vida, honra, integridade física e psíquica etc., mas não se exaurindo a esses, em decorrência da dignidade humana, o presente estudo passa a analisar a necessidade de proteção desses direitos a um grupo específico: mulheres, o que aqui se denominará de personalidade feminina.

As reivindicaçóes por reconhecimento das diferenças, em torno do multiculturalismo, encampadas pelos direitos humanos, em busca da promoção e respeito pela humanidade, tornam-se predominantes em movimentos sociais como o feminismo (FRASER, 2010, p. 115). A luta das mulheres, como destaca Bruna Lazaretti e Dirceu Siqueira (2017, p. 51), está focada na libertaçáo feminina da cultura machista e um senso moral constituída por aquela que se protraiu no tempo e, como concluiu Gilberto Freyre, ao estudar o patriarcalismo do Brasil, houve um conjunto de fatos que levou a acentuar 
diferenças entre o corpo da mulher, como frágil e delicado, ao do homem, como forte para dominaçáo daquele, que perpassou para forma de tratamento, etiqueta moral, para a literatura idealizando aquela mulher, e se faz necessária a transcrição que se compreenda a impregnação da cultura machista, que até hoje, idealiza um padrão de conduta social, moral e estético às mulheres:

Mas todo um conjunto de fatos nos autoriza a concluir pela artificialidade ou pela morbidez do tipo da mulher franzina ou langue, criado pelo sistema patriarcal de sociedade e em torno do qual desabrochou, no Brasil como em outros países de formação patriarcal, não só uma etiqueta de cavalheirismo exagerado, de Minha Senhora, Ex.ma Senhora Dona, Excelentíssima, como uma literatura profundamente erótica de sonetos e quadras, de novelas e romances, com a figura de Elvira ou Clarice, de Dolores ou Idalina, ora idealizada em extremo, ora exaltada pelas sugestôes de seu corpo especializado para o amor físico. De seus pezinhos mimosos. De suas mãos delicadas. De sua cintura estreita. De seus seios salientes e redondos. De tudo que exprimisse ou acentuasse sua diferença física do homem; sua especialização em boneca de carne para ser amolegada pelo homem. Pela imaginaçáo do poeta e pelas mãos do macho. O culto pela mulher, que se reflete nessa etiqueta e nessa literatura, e também numa arte igualmente erótica - uma música açucarada, uma pintura romântica, cor-de-rosa, uma escultura sem outra coragem que a do gracioso, a não ser a do nu (mas não o puro, e sim o obsceno); esse culto pela mulher, bem apurado, é, talvez, um culto narcisista do homem patriarcal, do sexo dominante, que se serve do oprimido - dos pés, das mãos, das tranças, do pescoço, das coxas, dos seios, das ancas da mulher, como de alguma coisa de quente e doce que the amacie, lhe excite e lhe aumente a volutuosidade e o gozo. O homem patriarcal se roça pela mulher macia, frágil, fingindo adorá-la, mas na verdade para sentir-se mais sexo forte, sexo nobre, mais sexo dominador. (FREYRE, 2013, p. 132).

Como bem destaca Carla Garcia (2015, p. 09) não se nega, em geral, a necessidade de enfoque nas questôes de gênero, entretanto, é comum que se desgoste quando o termo feminismo é utilizado, por vezes acaba por descredibilizar o intento feminista. Ocorre que os feminismos - e aqui se toma o cuidado desse proposital plural para deixar claro que náo se trata de um movimento único, mas uma série de movimentos, cada qual com suas particularidades atinentes à questóes únicas, como o feminismo negro, que historicamente enfrenta obstáculos muito maiores desde os tempos da escravidáo brasileira o que legitima políticas públicas especiais, movimentos que se interseccionam em torno da cultura machista, misógina e sexista que ainda paira nos tempos atuais -, em breve consideração, são movimentos para esclarecimentos, promoção feminina, além de questionamento dos padróes culturais e morais impostos socialmente às mulheres, que interferem na autonomia feminina, na representatividade dessas.

Após a Segunda Guerra Mundial, em que o mundo político e jurídico passava por uma reestruturação para atender ao clamor de paz e justiça social, houve uma política internacional para a igualdade de gênero, como estudou Ana Paula Martins (2018, p. 03). E, no Brasil, embora "com o movimento militar de 1964, as associações femininas praticamente desapareceram, notadamente aquelas que desenvolviam açóes políticas 
mais consistentes" (TABAK, 1983, p. 127), destaca-se que na década de 70 o movimento feminista, a nível global, impulsionou os assuntos e influenciou a Organização das Nações Unidas - ONU a adotar a Convenção sobre a Eliminação de todas as formas de Discriminação contra a Mulher (CEDAW), em 1979, que influenciou fortes modificaçóes nas legislaçóes internas dos Estados-membros (MARTINS, 2018, p. 03). De outro lado, "a Convenção sobre a eliminação de todas as formas de discriminação contra a mulher enfrenta o paradoxo de ser o instrumento que recebeu o maior número de reservas formuladas pelos Estados, dentre os tratados internacionais de direitos humanos" (PIOVESAN, 2010, p. 210).

Junior Xavier Fonseca, ao estudar a ausência de representatividade feminina no ambiente política, alerta para a nocividade do desenvolvimento da personalidade feminina ao descrever a existência de discriminação em razão do gênero, como um indivíduo indigno de apoio político e investimento para consolidação dessa carreira, que "revela a existência de uma ofensa à sua honra subjetiva, posto que se sente diminuída em seus valores pelo fato de ser do sexo feminino" (FONSECA, 2018, p. 15). O que nutre esse sentimento de inferioridade feminina, não só na representatividade política, mas no próprio exercício da democracia direta, além do desconhecimento dos seus direitos, é a cultura machista que se protraiu no tempo.

Os feminismos, esses movimentos sociais buscam a ruptura desse padrão, claramente se trata de um grupo de interesse, como se verificou, no capítulo anterior, pela atuação de defensoras em prol dos direitos das mulheres, em audiência pública na Arguição de Descumprimento de Preceito Fundamental (ADPF) no 54, no Supremo Tribunal Federal. E, considerando que se trata em temas relacionados aos direitos das mulheres, há atributos e caracteres essenciais dessas mulheres atinentes à dignidade humana, ao mesmo passo em que a proteção à dignidade humana, como defende Pedro Rezende (2018, p. 64), é tarefa central do ordenamento para proteção e tutela dos direitos da personalidade humana.

A audiência pública, com a atividade do lobby, apresenta-se como fortes instrumentos democráticos para ponderação dos atributos essenciais à personalidade feminina, que serão destacados caso a caso, em busca de uma ressignificação política e social. A consideração do cidadáo como ser individual e plural foi tratada por David Rúbio para consciência e cultura jurídica de direitos humanos para a participação social, nos seguintes termos:

Todo ser humano, en lo individual y en lo colectivo, a partir del_ reconocimiento de las condiciones para la producción, reproducción y el desarrollo de la vida corporal y concreta de cada uno y cada una, por medio del igual acceso a los bienes que proporcionan la satisfacción existencial de sus necesidades, debe tener la posibilidad instituyente y, como sujeto plural y diferenciado, de significar y resignificar la realidad de sus entornos relacionales sin discriminaciones, marginaciones y dominaciones raciales, de clase, sexuales, genéricas, etarias, étnico-culturales y/o por razones de discapacidad 
psíquica o física. No se trata solo de incrementar una conciencia y una cultura jurídica de protección, sino, además, potenciar una cultura de derechos humanos en general, integral y que acentúe la dimensión pre-violadora desde donde más se construyendestruyen y articulan-desarticulan porque, en realidad, somos todos los seres humanos ahí donde nos movemos, quienes, utilizando o no utilizando la vía jurídica, participamos en los procesos de construcción o destrucción de derechos humanos, seamos o no seamos juristas, teóricos y/o operadores jurídicos. (RUBIO, 2017, p. 58-59).

O presenteestudo defende, portanto, na linha de raciocínio de Jéfferson Casagrande, que os direitos da personalidade podem ser tangidos e defendidos em audiências públicas no judiciário, por se tratar de um mecanismo democrático de participaçáo direta ou participativo, concebido pela Constituição de 1988 (CASAGRANDE, 2018, p. 128). No mesmo sentido, Dirceu Siqueira e Bruna Souza destacam a importância do Poder Judiciário para adequação normativa à realidade social, especialmente no Supremo e ao interesse dos direitos da personalidade:

Ademais, e vislumbrando a importância que o poder judiciário possui no sentido de ser nele que a adequação da norma "in abstrato" à realidade social se faz presente, às audiências públicas tornam-se de importância ímpar no processo jurisdicional, em especial quando envolve o Supremo Tribunal Federal com o debate de matérias de cunho constitucional e com grande interesse social, inclusive de direitos da personalidade, vigorando-se, desta forma, como um mecanismo de aproximação ainda maior dos magistrados à realidade vigente e aos anseios sociais que envolvem aquela decisão, sem deixar de lado, todavia, o papel exercido por essa corte, por exemplo, como o tutor desse procedimento e detentor da última palavra. (SIQUEIRA; SOUZA, 2019, p. 284)

Resta reiterar, portanto, que decorrente da dignidade humana, prevista constitucionalmente como fundamento do Estado democrático de direito brasileiro, e, existente um grupo específico vulnerável, em razão do gênero, as mulheres, se faz necessária uma proteção aos direitos da personalidade feminina, atributos essenciais ao desenvolvimento do gênero mulher, seja a autonomia, integridade física, psíquica ou outro atributo dessa parcela que devem ser levados para ponderação, ou consideração, no controle de constitucionalidade concentrado que se faz no Supremo Tribunal Federal.

\section{Conclusáo}

Lobby, instrumento democrático de pressáo, pelo fundamento constitucional de liberdades para manifestação de pensamento, associação, reunião em locais abertos, de obter informações de órgãos públicos e ao direito de petição aos poderes públicos, ainda é pouco estudado e utilizado por associaçóes civis. Nesse sentido, o lobby exercido em audiências públicas parece como complemento a este outro instrumento de participaçáo popular. $\mathrm{O}$ instrumento democrático da audiência pública possibilita a participaçáo direta e indireta dos cidadãos a participarem das decisóes da Administração Pública, 
quando a temática for atinente aos direitos e interesses coletivos ou difusos e houver previsão normativa para convocação.

A problemática do presente estudo, que buscou responder em que medida a existência do lobby em audiência pública, no âmbito do Supremo Tribunal Federal, auxiliaria os direitos da personalidade feminina, apontou para a autêntica participaçáo democrática de grupos de interesses, no caso em prol dos direitos das mulheres, para exercer pressão e, assim, estimular a promoção e resguardo aos atributos femininos decorrentes da dignidade humana.

Em um panorama geral, as audiências públicas no Brasil, junto Poder Judiciário, especificamente no âmbito do Supremo Tribunal Federal (STF), onde se realiza o controle concentrado de constitucionalidade, apresentam falhas atinentes à realização do ato. $\mathrm{O}$ presente estudo buscou analisar os principais estudos na temática e, assim, identificou: (i) baixa participação da comunidade; (ii) desinformação da população sobre os direitos em discussão, sobre a possibilidade da participação; (iii) baixa presença dos ministros; (iv) discricionariedade para convocação; (v) condução falha, que compromete o diálogo e inibe a população presente.

Observou-se, a partir das constataçóes identificadas, que as audiências públicas perante o STF necessitam de um melhor uso para, além da busca por uma decisão efetiva, informar a população sobre os instrumentos de participação democrática. Dessa forma, o estudo aqui desenvolvido propóe como pertinente àquela necessidade, o auxílio pelo lobby, isso porque se observou que grupos de interesses têm mais êxito de influência do que quando da participação individual.

Constatou-se, especificamente em relação aos lobbies no Poder Judiciário, por audiências públicas junto ao Supremo Tribunal Federal, que um grupo de interesse se mostra mais eficaz do que indivíduos particulares sozinhos, isto é, em participação direta na audiência pública. A constatação foi feita a partir de estudos sobre a Arguição de Descumprimento de Preceito Federal - ADPF no 54, sobre a interrupção da gravidez de fetos anencéfalos, que, em audiência pública no STF, participou um grupo de defensoras em prol dos direitos das mulheres que questionaram, desmistificaram e levaram informaçóes. Em consequência, seus argumentos foram utilizados nos votos e influenciaram a decisão final, que se mostrou como uma grande vitória aos direitos das mulheres, que passaram, com a decisão do Supremo, a contar com a faculdade de interromper a gravidez de feto anencéfalo, o que se denominou de antecipação terapêutica do parto.

Referente à necessidade de proteção jurídica aos direitos da personalidade feminina, incialmente, o estudo apresentou uma noção básica ao instituto (direitos da personalidade) a partir dos principais trabalhos da área, que corresponde à proteção dos atributos e caracteres essenciais ao indivíduo para seu pleno desenvolvimento, cujo fundamento é a dignidade da pessoa humana, logo, não possui um rol exaustivo. 
Constatou-se que esses direitos da personalidade, que protegem os aspectos como integridade física, psíquica e moral da pessoa podem, e devem, ser defendidos em audiência pública, principalmente por grupos de interesse no formato de lobby, devido sua influência lícita na decisão, pois levam à conhecimento da Administração a opinião e experiência da parcela interessada/afetada.

Analisou-se, especificamente em relaçáo à personalidade feminina, que a proteçáo jurídica aos atributos essenciais das mulheres, se faz pertinente e necessária pelas vias de lobby em audiência pública, na medida em que os grupos de interesse, em prol daquele grupo, estão mais aptos a obter êxito, de influenciar a decisão, do que mulheres ouvidas individualmente para demonstrarem sua experiência e opinião.

Analisada a participação em audiência pública por grupo de interesse, constatouse que a pressão exercida pelos grupos de interesse se estende para além da decisão embora se reconheça que essa atinge elevado número de pessoas -, importa destacar que o lobby tem também por finalidade o alcance a longo prazo para: formaçáo de agenda, de política pública, servir para alcançar novos horizontes e efetivaçóes, assim como auxilia na necessária informação populacional que, ainda, desconhece seus direitos e garantias.

O resultado, isto é, os estudos já realizados na temática de lobby no Judiciário brasileiro, que são poucos, entretanto, recentes e aprofundados revelam que o instrumento democrático é promissor para a participação e informação popular, embora ainda seja alvo de estigma advindo do lobby ilícito - que permeiam, principalmente, nos cenários políticos brasileiros de corrupção, favorecimento de empresas e interesses particulares.

\section{Referências}

ALBANO, Denise Leal. Judicialização da vida, "descoletivização" dos direitos fundamentais sociais e o "desvio" judicante. Revista culturas jurídicas. UFF. v. 2, n. 3, pp. 182-198, 2015. Disponível em: http://www.culturasjuridicas.uff.br/index.php/rcj/ article/view/48. Acesso em: 03 jun. 2020.

ALBUQUERQUE, Newton de Menezes. A autofagia no Supremo Tribunal Federal: uma análise dos desdobramentos da monocratização à luz da teoria da soberania de Jean Bodin. Revista culturas jurídicas. UFF. v. 7, n. 16, pp. 97-118, 2020. Disponível em: http://www.culturasjuridicas.uff.br/index.php/rcj/article/view/799. Acesso em: 04 jun. 2020.

ALVES, Fernando de Brito; RIGÃO, Livia Carla Silva. Cultura da periferia e as cançóes de rap: um olhar para as "vozes silenciadas" a partir da filosofia de Enrique Dussel.

Revista Direitos Sociais e Políticas Públicas - Unifafibe. V. 8, N. 1, 2020.

ASCENSÃO, José de Oliveira. Direito civil: teoria geral. v. 1, 2. ed. Coimbra: Coimbra, 2000. 
BARROSO, Luís Roberto. O controle de constitucionalidade no direito brasileiro. 6. ed. rev. e atual. São Paulo: Saraiva, 2012.

BORGES, Gustavo SILVEIRA; CARVALHO, Marina Moura Lisboa Carneiro de Farias. Os "novos" direitos e a irrupção da proteção constitucional dos direitos da natureza. Revista culturas jurídicas. UFF. v. 06, n. 13, pp. 188-207, 2019. Disponível em: http://www.culturasjuridicas.uff.br/index.php/rcj/article/view/448. Acesso em: 02 jun. 2020.

BRASIL. Constituição da República Federativa do Brasil de 1988. Disponível em: http://www.planalto.gov.br/ccivil_03/constituicao/constituicao.htm. Acesso em: 28 abr. 2020.

BRASIL. Lei no 9.868, de 10 de novembro de 1999. Disponível em: http://www. planalto.gov.br/ccivil_03/leis/19868.htm. Acesso em: 03 jun. 2020.

BRASIL. Lei no 9.882, de 03 de dezembro de 1999. Disponível em: http://www. planalto.gov.br/ccivil_03/leis/19882.htm. Acesso em: 03 jun. 2020.

CANOTILHO, José Joaquim Gomes. Direito constitucional e teoria da Constituição. 3. ed. Coimbra: Livraria Almedina, 1999.

CANTALI, Fernanda Borghetti. Direitos da personalidade: disponibilidade relativa, autonomia privada e dignidade humana. Porto Alegre: Livraria do advogado, 2009.

CAPPELLETTI, Mauro. Acesso à justiça. GARTH, Bryant (Colab.). Tradução: Ellen Gracie Northfleet. Porto Alegre: Fabris, 1998.

CASAGRANDE, Jéfferson Ferreira. A audiência pública é uma forma de exercício do ativismo judicial na efetivaçáo dos direitos da personalidade? Dissertação (Mestrado em Direito). Maringá, PR: UniCesumar, 2018. Disponível em: http://rdu.unicesumar. edu.br/xmlui/handle/123456789/1023. Acesso em: 25 abr. 2020.

CASTRO, Alexander; NASCIMENTO, Gabriel Bassaga. Liberdade de expressão frente à liberdade religiosa: direitos fundamentais em conflito e proteção de direitos da personalidade frente a discursos de ódio. Revista Direitos Sociais e Políticas Públicas - Unifafibe. V. 7, N. 3, 2019.

CASTRO, Marcus Faro de. Globalização, democracia e direito constitucional: legados recebidos e possibilidades de mudança. in: CLÈVE, Clèmerson Merlin; FREIRE, Alexandre (Org.). Direitos fundamentais e jurisdição constitucional: análise, crítica e contribuiçôes. pp. 697-719. Sáo Paulo: Revista dos Tribunais, 2014.

COCHRAN III, Augustus Benner. Democracy is more than choice: the necessity of voice. Revista jurídica. UniCuritiba. v. 4, n. 49, pp. 01-26, 2017. Disponível em: http://web.a.ebscohost.com/ehost/pdfviewer/pdfviewer?vid=0\&sid=8d2124d9-67134742-b819-5c5d5321daba\%40sessionmgr4007. Acesso em: 02 jun. 2020. 
COLLINS JR., Paul M. Lobbyists before the U.S. Supreme Court: investigating the influence of amicus curiae briefs. Political research quartely. University of Utah. v. 60, n. 01, pp. 55-70, 2007. Disponível em: https://journals.sagepub.com/ doi/10.1177/1065912906298535. Acesso em: 03 jun. 2020.

COSTA, Fabrício Veiga; PINTO, Alisson Alves. A ressocialização do detento a partir do prazo para o cumprimento da funçáo social da empresa na sociedade contemporânea.

Revista Direitos Sociais e Políticas Públicas - Unifafibe. V. 7, N. 3, 2019.

DAL BOSCO, Maria Goretti. Audiência pública como direito de participação. Revista jurídica UNIGRAN. Dourados, v. 4, n. 8, pp. 137-157, 2002.

DIANA, Gilson Matilde. Direito constitucional contemporâneo e os desafios dos direitos fundamentais: a liberdade e autonomia da vontade e a antecipação terapêutica do parto no caso de fetos anencéfalos. Revista culturas jurídicas. UFF. v. 2, n. 4, pp. 81-102, 2015. Disponível em: http://www.culturasjuridicas.uff.br/index.php/rcj/ article/view/139. Acesso em: 02 jun. 2020.

EBERHARDT, Maria Laura. ¿ El fin de la democracia representativa? Otras modalidades democráticas: participación y deliberación ciudadana. Revista direitos fundamentais \& democracia. UniBrasil, v. 18, n. 18, pp. 182-227, 2015. Disponível em: http://web.a.ebscohost.com/ehost/pdfviewer/pdfviewer?vid=0\&sid=8d2124d96713-4742-b819-5c5d5321daba\%40sessionmgr4007. Acesso em: 03 jun. 2020.

FERMENTÃO, Cleide Aparecida Gomes Rodrigues. Os direitos da personalidade como direitos essenciais e a subjetividade do direito. Revista jurídica Cesumar mestrado. v. 6, n. 1, pp. 241-266, 2006. Disponível em: https://periodicos.unicesumar. edu.br/index.php/revjuridica/article/view/313. Acesso em: 26 abr. 2020.

FONSECA, Junior Xavier. Obstáculos e desafios ao desenvolvimento da personalidade da mulher no cenário político brasileiro. Dissertação (Mestrado em Ciências Jurídicas). Maringá, PR: UniCesumar, 2018. Disponível em: http://rdu. unicesumar.edu.br/xmlui/handle/123456789/998. Acesso em: 26 abr. 2020.

FRASCATI JUNIOR, Nicola. A ética processual como garantia dos direitos da personalidade e o acesso à justiça. Dissertação (Mestrado em Ciências Jurídicas). Maringá: UniCesumar, 2017.

FRASER, Nancy. Repensando o reconhecimento. Tradução: Edna Velloso de Luna. Revista enfoques. UFRJ, v. 09, n. 01, pp. 114-128, agosto 2010. Disponível em: http://enfoques.ifcs.ufrj.br/ojs/index.php/enfoques/article/view/102/0. Acesso em: 03 jun. 2020.

FREYRE, Gilberto. Sobrados e mucambos: decadência do patriarcado rural e desenvolvimento urbano. Introdução à história da sociedade patriarcal no Brasil - 2 . São Paulo: Global, 2013. 
GARCIA, Carla Cristina. Breve história do feminismo. 3. ed., São Paulo: Claridade, 2015. ISBN-978-85-88386-63-1. 120 p. (E-book kindle).

GORDILLO, Augustín. Tomo 2, La defensa del usuario y del administrado. Tratado de derecho administrativo y obras selectas. Buenos Aires: F.D.A., 2014.

GOZETTO, Andréa C. Oliveira; MANCUSO, Wagner P. Lobby e participação política: desafios democráticos para a representação de interesses. 8. Encontro da Associaçáo Brasileira de Ciência Política. Gramado: Rio Grande do Sul, 2012.

GUIMARÃES, Lívia Gil. Atuação do movimento das mulheres no Supremo Tribunal Federal: litígio estratégico no caso da ADPF 54. Revista brasileira de estudos constitucionais - RBEC. Ano 120, n. 40, pp. 13-37, 2018.

GUIMARÁES, Lívia Gil. Participação social no STF: repensando o papel das audiências públicas. Revista direito e praxis. UERJ. Rio de Janeiro, v. 11, n. 01, pp. 236-271, 2020. Disponível em: https://www.e-publicacoes.uerj.br/index.php/ revistaceaju/article/view/36633. Acesso em: 01 jun. 2020.

HAKMAN, Nathan. Lobbying the Supreme Court: an appraisal of "political science folklore”. Fordham law review. v. 35, n. 1, pp. 15-50, 1966. Disponível em: https:// ir.lawnet.fordham.edu/flr/vol35/iss1/2/. Acesso em: 05 jun. 2020.

KIRSTE, Stephan. O direito fundamental à democracia. Tradução: Marcos Augusto Maliska. Revista direitos fundamentais \& democracia. UniBrasil. v. 20, n. 20, pp. 05-38, 2016. Disponível em: http://web.b.ebscohost.com/ehost/pdfviewer/ pdfviewer?vid=0\&sid=f1b651 e6-8ee0-49ce-a951-9fe2e2dc7d00\%40pdc-v-sessmgr03. Acesso em: 03 jun. 2020.

LAZCANO, Alfonso Jaime Martínez. El derecho convencional y los retos de su implementación en los estados parte. Revista Direitos Sociais e Políticas Públicas Unifafibe. v. 7, n. 3, 2019.

LIMA, Edilson Vitoreli Diniz. O devido processo legal coletivo: representação, participação e efetividade da tutela jurisdicional. Tese (Doutorado em Direito). Curitiba: UFPR, 2015. Disponível em: https://acervodigital.ufpr.br/ handle/1884/40822. Acesso em: 10 jun. 2020.

LOZANO, Luis Gerardo Rodrígues. León duguit y el servicio público: ideas para el siglo XXI. Revista Direitos Sociais e Políticas Públicas - Unifafibe. V. 8, N. 1, 2020.

LUCAS, Doglas Cesar. Direitos humanos, identidade e a política de reconhecimento de Charles Taylor. Revista Direitos Sociais e Políticas Públicas - Unifafibe. v. 7, n. 3, 2019.

LUHMANN, Niklas. Legitimação pelo procedimento. Tradução: Maria da Conceição Côrte Real. Brasília: Universidade de Brasília, 1980. 
MAGLIACANE, Alessia. L'armee des reserves dans la mondialisation: la parabole de la femme italienne de la constitution au post-fordisme. Revista Direitos Sociais e Políticas Públicas - Unifafibe. v. 7, n. 3, 2019.

MARTÍN, Ignacio Durbán. Origen y fundamentos del sistema plurilegislativo civil español. Revista Direitos Sociais e Políticas Públicas - Unifafibe. v. 8, n. 1, 2020.

MARTINS, Ana Paula Martin. 7. Reflexôes sobre igualdade de gênero e os organismos internacionais. Gênero, direito e relaçóes internacionais: debates de um campo em construção. VITALE, Denise; NAGAMINE, Renata. (Organizadoras). Salvador: EDUFBA, 2018. ISBN: 978-85-232-1863-8. (E-book kindle).

MORAES, Maria Valentina de; LEAL, Mônia Clarissa Hennig. Supremo Tribunal Federal e diálogo institucional: há um controle jurisdicional de políticas públicas no Brasil? Revista Direitos Sociais e Políticas Públicas - Unifafibe. v. 7, n. 3, 2019.

MOREIRA NETO, Diogo de Figueiredo. Audiências públicas. Revista de direito administrativo. Rio de Janeiro. v. 210, pp. 11-23, 1997. Disponível em: http:// bibliotecadigital.fgv.br/ojs/index.php/rda/article/view/47084. Acesso em: 01 jun. 2020.

OLIVEIRA, Gustavo Henrique Justino de. As audiências públicas e o processo administrativo brasileiro. Revista de informaçáo legislativa. Brasília, DF, a. 34, n. 135, pp. 271-282, 1997. Disponível em: https://www2.senado.leg.br/bdsf/bitstream/handle/ $\mathrm{id} / 280 /$ r135-31.pdf?sequence=4\&isAllowed=y. Acesso em: 01 jun. 2020.

OLIVEIRA, Marcelo Andrade Cattoni de. Direito, política e filosofia: contribuiçóes para uma teoria discursiva da constituição democrática no marco do patriotismo constitucional. Rio de Janeiro: Lumen Juris, 2007.

OLSON, Susan M. Judicial Branch lobbying in the United States. in: Research guide to U.S. and international interest groups. Clive Thomas (Org.). Cap. 7.12, pp. 179181. Westport: Praeger, 2004.

PIOVESAN, Flávia. Direitos humanos e o direito constitucional internacional. 11 ed. São Paulo: Saraiva, 2010.

REALE, Miguel. Os direitos da personalidade. Disponível em: http://www. miguelreale.com.br/artigos/dirpers.htm. Acesso em: 27 abr. 2020.

REZENDE, Pedro Roderjan. Tutelas preventivas para proteção dos direitos da personalidade e seus limites à luz do pós-positivismo. Dissertação (Mestrado em Ciências Jurídicas). Maringá-PR: UniCesumar, 2018.

RÚBIO, David Sanchez. Crítica a una cultura estática y anestesiada de Derechos Humanos: por una recuperación de las dimensiones constituyentes de la lucha por los derechos. Revista culturas jurídicas. UFF. v. 4, n. 7, pp. 26-60, 2017. Disponível em: 
http://www.culturasjuridicas.uff.br/index.php/rcj/article/view/370. Acesso em: 02 jun. 2020.

SARMENTO, Daniel. Dignidade da pessoa humana: conteúdo, trajetórias e metodologia. Belo Horizonte: Fórum, 2016.

SILVA, De Plácido e. Vocabulário Jurídico. Atualização de Nagib Slaibi Filho e Gláucia Carvalho. 23.ed. Rio de Janeiro: Forense, 2003.

SIQUEIRA, Dirceu Pereira; LAZARETTI, Bruna Furini. Representatividade e liderança feminina nas grandes corporaçóes: uma leitura sob a perspectiva dos movimentos sociais. Revista juris poiesis. Universidade de Sá. Rio de Janeiro, v. 20, pp. 45-67, 2017. Disponível em: http://periodicos.estacio.br/index.php/jurispoiesis/ article/viewFile/3873/1716. Acesso em: 26 abr. 2020.

SIQUEIRA, Dirceu Pereira; SOUZA, Bruna Caroline Lima de. Democratização da justiça: audiências públicas, poder judiciário e os direitos da personalidade. Revista Húmus. UFMA, v. 9, n. 27, pp. 263-289 2019. Disponível em: http://www. periodicoseletronicos.ufma.br/index.php/revistahumus/article/view/12351. Acesso em: 02 jun. 2020.

SOMBRA, Thiago Luis. Why should public hearings in the brazilian Supreme Court be understood as an innovative democratic tool in constitutional adjudication? German law journal. V. 17, n. 4, pp. 657-690, 2016. Disponível em: https:/www. cambridge.org/core/journals/german-law-journal/article/why-should-public-hearingsin-the-brazilian-supreme-court-be-understood-as-an-innovative-democratic-tool-inconstitutional-adjudication/6B02BB2C9ED6D030DBA68EAA755524C3. Acesso em: 2 jun. 2020.

SZANIAWSKI, Elimar. Direitos da personalidade e sua tutela. Sáo Paulo: Revista dos Tribunais, 1993.

TABAK, Fanny. Autoritarismo e participação política da mulher. Coleção Tendência. v. 6. Rio de Janeiro: Graal, 1983.

THOMAS, Clive S. Introduction: The study of interest groups. in Research guide to U.S. and international interest group. THOMAS, Clive S. (Org.). Cap. 1. pp. 01-23. Westport: Praeger, 2004.

TUSHNET, Mark. New institutional mechanisms for making constitutional law. Harvard Public Law Working Paper. n. 15-08, 2015. Disponível em: http://papers.ssrn.com/ abstract $=2589178$. Acesso em: 04 jun. 2020.

VASCONCELOS, Antonio Gomes de; SOARES, Mirelle Fernandes. Audiência pública no exercício da jurisdição no Estado constitucional democrático. Revista Direito e Liberdade. Escola da Magistratura do Rio Grande do Norte (ESMARN), v. 17, n. 3, p. 29-48, set./dez. 2015. Disponível em: https://eds.b.ebscohost.com/eds/ 
detail/detail?vid=0\&sid=0724f851-0e05-46c1-ac4b-b7897981d6ea\%40sessionmgr101 \&bdata=Jmxhbmc9cHQtYnImc210ZT11ZHMtbGl2ZQ\%3d\%3d\#AN=edsbas.837596 $38 \& \mathrm{db}=$ edsbas. Acesso em: 5 jun. 2020.

YOUNG, Iris Marion. Inclusion and democracy. Oxford: Oxford University Press, 2002.

ZANINI, Leonardo Estevam de Assis. Direitos da personalidade. São Paulo: Saraiva, 2011. 